\title{
Application of artificial neural network to predict amount of carried weight of cargo train in rail transportation system
}

\author{
Siti Nasuha Zubir ${ }^{1}$, S. Sarifah Radiah Shariff ${ }^{2}$, Siti Meriam Zahari ${ }^{3}$ \\ 1,2, ${ }^{3}$ Centre for Statistics and Decision Science Studies, Faculty of Computer and Mathematical Sciences, Universiti \\ Teknologi MARA, Shah Alam, Selangor, Malaysia \\ ${ }^{2}$ Malaysia Institute of Transport, Universiti Teknologi MARA, Shah Alam, Selangor, Malaysia
}

\begin{tabular}{l} 
Article Info \\
\hline Article history: \\
Received Feb 1, 2020 \\
Revised Apr 22, 2020 \\
Accepted May 24, 2020 \\
\hline
\end{tabular}

\section{Keywords:}

Artificial neural network Carried weight

Conjugate gradient descent

Levenberg-marquardt

Quick propagation

\begin{abstract}
Derailments of cargo have frequently occurred in Malaysian train services during the last decade. Many factors contribute to this incident, especially its total amount of carried weight. It is found that severe derailments cause damage to both lives and properties every year. If the amount of carried weight of cargo train could be accurately forecasted in advance, then its detrimental effect could be greatly minimized. This paper presents the application of Artificial Neural Network (ANN) to predict the amount of carried weight of cargo train, with KTMB used as the study case. As there are many types of cargo being carried by KTMB, this study focuses only on cement that being carried in twelve (12) different routes. In this study, Artificial Neural Network (ANN) has been incorporated for developing a predictive model with three (3) different training algorithms, Levenberg-Marquardt (LM), Quick Propagation (QP) and Conjugate Gradient Descent (CGD). The best training algorithm is selected to predict the amount of carried weight by comparing the error measures of all the training algorithm which are Root Mean Squared Error (RMSE) and Mean Absolute Percentage Error (MAPE). The obtained results indicated that the ANN technique is suitable for predicting the amount of carried weight.
\end{abstract}

This is an open access article under the CC BY-SA license.

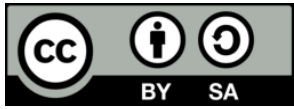

\section{Corresponding Author:}

S. Sarifah Radiah Shariff,

Malaysia Institute of Transport,

Universiti Teknologi MARA,

Shah Alam, Selangor, Malaysia.

Email: shari990@uitm.edu.my

\section{INTRODUCTION}

Cargo or freight refers to goods or product that are transferred of distributed generally for commercial gain. Nowadays, cargo transport can be carried on water, air or land. Most widely used to carry cargo is road transport. Different form of weight and vehicle are used to transport cargo around. Road transport has many advantages like it can do door to door delivery on top of having several type of vehicles like trucks, busses, lorry, cars and so on. However, some bulky items like sugar, cements, charcoals that need to be transferred in large volume are moved using train or rail transport.

Other than known as able to carry passengers, train is also capable of transporting large volume of items such as water, cement, steel, wood and coal. Generally, train cargo has a direct route to its destination. Under the right condition, cargo transport by rail is more economic and more productive compared to road transport, especially when transporting items in large volume over long distance. The choice of mode of transportation depends very much on carried weight. Carried weight is an important matter in transport 
system and need to be considered. In the logistic transportation system, the amount of weight carried is very important to ensure that all the goods arrive safely at the destination in time. Using train as mode of transportation is beneficial to the environment as it is limiting greenhouse gas emissions, increasing fuel efficiency and reducing its carbon footprint [1].

KTMB Freight Service has three types of train services: Train Contena Service, Train Cargo Conventional Service and Train Landbridge Service. In 2017, KTMB has experienced three major derailments. On August 21, 2017, a cargo train crashed at Jalan Kucing, causing delays for a few days [2]. On September 23, 2017, KTMB's cargo train snapped electrical cable between Rawang and Kuang stations and forcing KTMB to close all tracks for two days [3]. On November 23, 2017, once again another cargo train accidents occurred when twelve cargo trains travelling southward between the National Bank Station and Kuala Lumpur Station slipped due to heavy weight and oversized loads carried by the cargo trains. As a result, KTM and ETS services were disrupted on several routes around the Klang Valley. One of the major causes of this tragedy is the overloading of the cargo train's wagon [4]. In recent accident that occurred on 21 July 2019 cargo train that carried 30 wagons of cement. During the derailment, KTMB needed to relocate all the wagons as soon as possible because all the KTMB's services were effected [5]. The derailment happened due to many factors and one of the most significant factors is the amount of carried weight. Having the amount of carried weight planned to match the track capability can avoid derailment occurrences. Artificial Neural Network (ANN) is a popular method used by other previous researchers to predict carried weight. In this study, the cargo train carried weight will be predicted.

The previous research outcomes demonstrated that the ANN is an efficient option strategy in prediction [6-10]. This is supported by [11-12] who proposed that ANN is the best model compared to Adaptive Neuro-Fuzzy Inference System (ANFIS). This study compared the models with American Concrete Institute and Iranian Concrete Institute empirical codes. As a result, the prediction of ANN is better than ANFIS model. In [13] developed a decision support system that can forecast demand in electronic retails industry at Turkey by using ANN techniques such as Gradient Descent (GD), the Conjugate Gradient Descent (GCD), Quick Propagation (QP) and LM methods. However, in multi - stage supply chain area the application of these artificial technique still have severe lack.

There are more studies focusing on how the predictive ability can be influenced by the training and testing algorithm. According to [14] in their study, ANN is used to predict carried weight and three (3) classes of ANN are used which are incremental back propagation algorithm (IBP), Genetic algorithm (GA) and Levenberg - Marquardt algorithm (LM). The predicting performance of the three algorithm was compared. This study was applied in an automobile industry, Iran Khodro Company (IKCO) as to appropriately provide the machinery resources, labor and transport system demand. ANN was used to test the weekly data of carried weight based on the observation of the number of vehicles and fuel consumption. At the end of the study, IBP give the optimum training algorithm. As for improvement, [15] used the same variable as the previous research to predict the carried weight. Instead of using GA and IBP, Quick Propagation (QP) and Batch Back propagation (BBP) are used and QP exhibits the better performance. Hence, this paper presents the application of Artificial Neural Network (ANN) to predict the amount of carried of cargo train, using three training algorithms: Levenberg - Marquardt algorithm (LM) as a well performed algorithm to predict different set of carried weight data, Conjugate Gradient Descent (GCD) as a well perform algorithm for prediction of other sets of data and Quick Propagation (QP) as a new algorithm used to predict carried weight.

\section{RESEARCH METHODS}

ANN is a mathematical model or computational model based on the neural networks or called an imitation of biological neural system. It is an adaptive system as it could modify the structure based on the information either internal or external that flow through the network [16]. This model is a flexible computing framework and a universal approximator. It can be applied to a wide range of problem like a time series forecasting with a high degree of accuracy. ANN replicates the biological neuron structure by creating a simple processing unit called artificial neurons. An approximation of the 3-dimensional intercoonectedness of biological neurones is done in ANN by means of the usage of layers. Figure 1 shows an ANN with input nodes, hidden nodes, and one output node. The hidden nodes will be generated using the different built-in algorithms. 


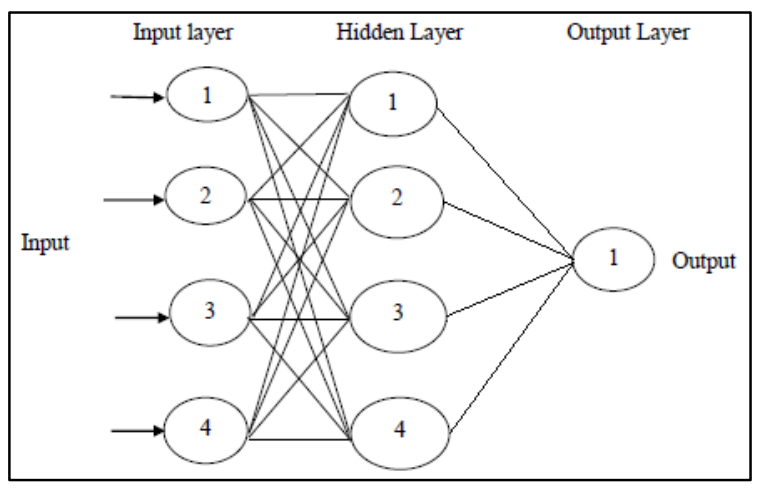

Figure 1. Artificial neural network model (ANN)

\subsection{Training algorithm}

Three built in training algorithms are used and compared.

a. Levenberg-Marquardt (LM)

It is a higher-order adaptive algorithm and it minimizes the Mean Square Error of a neural network [17]. LM algorithm is a variation of Newton's method that is designed for minimizing functions that are sums of squares of other nonlinear functions. LM algorithm provides numerical solution to minimized non-linear function. The (non-negative) damping parameter is adjusted in every iteration, where small values of the algorithmic parameter $\lambda$ result in Gauss-Newton update, and large values of $\lambda$ result in a gradient descent update. The parameter $\lambda$ is initialized to be large so that first updates are small steps in the steepest descent direction. If any iteration happens to lead to a poor approximation, then $\lambda$ is increased. Therefore, for large values of $\lambda$, the step will be taken approximately in the direction of the gradient. Otherwise, as the solution improves, $\lambda$ is decreased, the LM method approaches the Gauss-Newton method, and the solution typically accelerates to the local minimum.

b. Conjugate Gradient Descent (CGD)

The CGD method solves systems of linear equations, also used to solve system where matrix is not symmetric, not positive-definite, and still not square [18]. CGD is an advanced method for training multilayer neural network. In the CGD method, the line is not searched, but a plane is searched. A plane is formulated from a random linear combination of two vectors. For minimizing quadratic functions, the plane search requires only the solution of a two by two sets of linear equation for $\alpha$ and $\beta$. Solving convex optimization problems using CGD.

$$
f(x)=\frac{1}{2} x^{2}+\frac{1}{3} y^{2}+\frac{1}{5} x y
$$

Gradient Descent Method will try to find the minimum by computing the gradient of $(f)$ at the initial guess. To achieve the value of $x$ close to optimal solution the whole process has to iterate.

c. Quick Propagation (QP)

The Quick Propagation method uses the following updating equation:

$$
B_{i+1}=B_{i}+u_{i} p_{i}^{T}
$$

Where,

$$
\begin{aligned}
& u_{i}=\left(\Delta y_{i}-B_{i} p_{i}\right) / p_{i}^{T} p_{i} \\
& \triangle y_{i}=y_{i+1}-y_{i}
\end{aligned}
$$

$y_{i}$ is the model response for the ith iteration. The approximation of the Jacobian matrix $B_{i+1}$ for the $(i+1) t h$ iteration is calculated using the Jacobian matrix approximation $B_{i}$, the parameter perturbation vector $p_{i}$ and the change in the model response $\triangle y_{i}$ for the ith iteration. The updating matrix $u_{i} p_{i}^{T}$ is a rankone matrix and Broyden's method is a rank-one quick propagation method. The algorithm classified to the group of the second order learning method which is it follows a quadratic approximation of the previous gradient step and the current gradient [19]. 


\subsection{Error measures}

According to [20], forecasting error is about measuring how good the performance of a model itself compares to the one of using the past data.

a. Root Mean Squared Error (RMSE)

b. Mean Absolute Percentage Error (MAPE)

\subsection{Model validation}

The first stage is called initial data preparation. During the first stage, the data series will divided into two parts. The first part known as within samples or fitting parts that used to estimate the performance of forecasting model [21]. Meanwhile, the second part is to evaluate the model called as out samples or evaluation part. In this study, the data are partitioned into $70 \%$ for training part where as the $30 \%$ for validation part. There are 13,152 observation.

In the second stage, the within sample statistics is used to estimate the model using three built in algorithms, LM, CGD and QP. The best estimation approach is selected based on the outcomes of comparing their error measures performances [22]. For this purpose, RMSE and MAPE are used [23-24]. Training algorithm with the smallest error measure is decided to be able to produce the best fit model.

Having completed the first and second stages, the last stage is to use the best fit model to forecast the amount of carried weight by each train per trip, that can help KTMB to plan for its future operation.

\section{RESULTS AND DISCUSSION}

Predictive modeling using Artificial Neural Network were carried out by using Alyuda Neurointelligence software. In the first stage, data is treated for its missing values. Initially, there were 12 routes. Since, the missing values for some routes are more than $15 \%$ [25], then, those routes are omitted. The remaining two routes which are Route 1 and Route 2 are further analyzed and underwent imputation process by using IBM SPSS Modeler 18.0 software.

Table 1 shows the summary statistic for variables in Route 1 and Route 2 before imputation. There are three continuous and four categorical variables respectively. Only 1 categorical variable has missing value which is Labor in Route 1 and Route 2. While, there are missing values for all continuous variable which are Total Wagon, Tonnage/KM and Carried Weight for both routes. Therefore, imputation are needed for Labor and Total Wagon. However, Tonnage/KM will not undergo imputation process. For target variable which is Carried Weight, all the cases with the missing value are discarded for both routes.

Table 1. Summary statistics for variables

\begin{tabular}{clcccc}
\hline Station & & \multicolumn{2}{c}{ Route 1 } & \multicolumn{2}{c}{ Route 2 } \\
\hline Variable & Type & Valid & Mising & Valid & Missing \\
\hline Train no & Categorical & 1096 & 0 & 1096 & 0 \\
Company/Customer & Categorical & 1096 & 0 & 1096 & 0 \\
Distance & Categorical & 1096 & 0 & 1096 & 0 \\
Labour & Categorical & 922 & 174 & 844 & 252 \\
Total Wagon & Continuous & 905 & 191 & 900 & 196 \\
Tonnage/KM & Continuous & 1009 & 87 & 934 & 162 \\
Carried Weight & Continuous & 1009 & 87 & 934 & 162 \\
\hline
\end{tabular}

\subsection{Designing the network}

In order to choose the best training algorithm, the best network architecture is defined first. For Route 1 shown in Table 2, there were 8 iterations in finding the best network architecture. However, 6 network architectures which is in red colored has been removed in order to avoid over fit problem when the number of hidden nodes is greater than the number of input nodes. From the results, it was found that the best architecture is [5-5-1] model since it gives the largest fitness value, lowest test error and lowest AIC. Table 3 also shows that the best architecture for Route 2 is also [5-5-1] model. 
Table 2. Architecture network of ANN at route 1

\begin{tabular}{lllllll}
\hline ID & Architecture & Fitness & Test Error & AIC & Correlation & R-Squared \\
\hline 1 & {$[5-1-1]$} & 0.0859 & 11.6439 & -2825.6098 & 0.9941 & 0.9882 \\
2 & {$[5-13-1]$} & 0.2371 & 4.2173 & -3918.6457 & 0.9997 & 0.9994 \\
3 & {$[5-8-1]$} & 0.2057 & 4.8626 & -3635.6821 & 0.9994 & 0.9988 \\
4 & {$[5-5-1]$} & 0.2043 & 4.8949 & -3571.4968 & 0.9987 & 0.9974 \\
5 & {$[5-11-1]$} & 0.1751 & 5.7097 & -3551.4642 & 0.9992 & 0.9984 \\
6 & {$[5-9-1]$} & 0.1538 & 6.5036 & -3515.9084 & 0.9992 & 0.9984 \\
7 & {$[5-6-1]$} & 0.1716 & 5.8276 & -3633.2912 & 0.9992 & 0.9984 \\
8 & {$[5-7-1]$} & 0.1828 & 5.4696 & -3655.1763 & 0.9992 & 0.9984 \\
\hline
\end{tabular}

Table 3. Architecture network of ANN at route 2

\begin{tabular}{lllllll}
\hline ID & Architecture & Fitness & Test Error & AIC & Correlation & R-Squared \\
\hline 1 & {$[5-11-1]$} & 0.6865 & 1.4566 & -3896.9178 & 0.9998 & 0.9996 \\
2 & {$[5-9-1]$} & 0.6262 & 1.5969 & -3866.8793 & 0.9997 & 0.9994 \\
3 & {$[5-12-1]$} & 0.6085 & 1.6435 & -3794.2906 & 0.9997 & 0.9994 \\
4 & {$[5-10-1]$} & 0.5914 & 1.6908 & -3855.7806 & 0.9997 & 0.9994 \\
5 & {$[5-13-1]$} & 0.5288 & 1.8909 & -3739.4992 & 0.9997 & 0.9994 \\
6 & {$[5-8-1]$} & 0.4002 & 2.4989 & -3645.9149 & 0.9994 & 0.9988 \\
7 & {$[5-5-1]$} & 0.1217 & 8.2164 & -2886.5162 & 0.9971 & 0.9942 \\
8 & {$[5-1-1]$} & 0.1117 & 8.9540 & -2897.0075 & 0.9955 & 0.9910 \\
\hline
\end{tabular}

The fitness of training algorithms is also done in which Table 4 shows that LM produces the smallest value of Absolute and Network Error for both Route 1 and Route 2. Table 4 also shows that LM produces the smallest error value (RMSE and MAPE) for both training and validation parts for Route 1 and Route 2.

Table 4. Comparison of error measures for training algorithms

\begin{tabular}{|c|c|c|c|c|c|c|c|c|}
\hline \multicolumn{9}{|c|}{ Route 1} \\
\hline \multirow{2}{*}{$\begin{array}{c}\text { Training } \\
\text { Algorithm }\end{array}$} & \multicolumn{4}{|c|}{ Training } & \multicolumn{4}{|c|}{ Validation } \\
\hline & RMSE & MAPE & Absolute Error & Network Error & RMSE & MAPE & Absolute Error & Network Error \\
\hline CGD & 19.805 & 382.506 & 0.528 & 0.001 & 22.884 & 523.664 & 0.389 & 0 \\
\hline LM & 4.323 & 18.222 & 0.341 & 0 & 5.383 & 28.98 & 0.32 & 0 \\
\hline QP & 19.564 & 373.287 & 4.539 & 0 & 22.706 & 515.541 & 3.917 & 0 \\
\hline \multicolumn{9}{|c|}{ Route 2} \\
\hline \multirow{2}{*}{$\begin{array}{c}\text { Training } \\
\text { Algorithm }\end{array}$} & \multicolumn{4}{|c|}{ Training } & \multicolumn{4}{|c|}{ Validation } \\
\hline & RMSE & MAPE & Absolute Error & Network Error & RMSE & MAPE & Absolute Error & Network Error \\
\hline CGD & 5.532 & 29.843 & 4.5 & 0 & 57.294 & 3282.55 & 2.596 & 0 \\
\hline LM & 4.807 & 22.533 & 0.669 & 0 & 24.43 & 596.835 & 0.505 & 0 \\
\hline QP & 5.587 & 30.445 & 2.66 & 0 & 24.642 & 607.226 & 4.8 & 0 \\
\hline
\end{tabular}

\subsection{Forecasting by using the best training algorithm}

As previously discussed, the best training algorithm will be used for prediction of carried weight.

Hence, the ANN model with LM as the training algorithm is used to predict in both routes, Route 1 and Route 2.

The amount of carried weight forecasted for year 2019 at Route 1 is illustrated in Figure 2. The grey line represents the forecast value and the dotted orange line represents the trend line of the new forecasted values which negative slope indicates that amount of carried weight for Route 1 slightly decrease and going to decline over time. The trend line of the new forecasted carried weight values is constructed and it can be concluded that there is a decrease in amount of total tonnage carried each day by 0.0489 this due to negative relationship. The equation is $\mathrm{y}=-0.0489 \mathrm{x}+3249.8$. The forecast value shows that amount of carried weight fluctuates over time and decrease by $48.9 \mathrm{~kg}$ per day.

Then, the amount of carried weight forecast for year 2019 at Route 2 was illustrated in Figure 3. The grey line represents the forecast value and the dotted orange line represents the trend line of the new forecasted value. The forecasted line for Route 2 also is having a negative slope indicating that amount of carried weight for Route 2 slightly decreases over time. The trend equation is calculated, $\mathrm{y}=-0.1186 \mathrm{x}+$ 6079.3 which shows a decrease by $118.6 \mathrm{~kg}$ per day. Comparing the trend line of the new forecasted carried weight with earlier trend in Section 4.5.2, it can be seen that the decrease of average amount of carried weight for Route 1 slightly changes from $69.1 \mathrm{~kg}$ per day to only $48.9 \mathrm{~kg}$ per day. Therefore, it can be concluded that the amount of carried weight of cargo is increasing and cargo business is improving. 
On the other hand, for Route 2, the decrease of average amount of carried weight changes from $117.8 \mathrm{~kg}$ per day to $118.6 \mathrm{~kg}$ per day. However, the change is only $0.68 \%$ and very minimal.

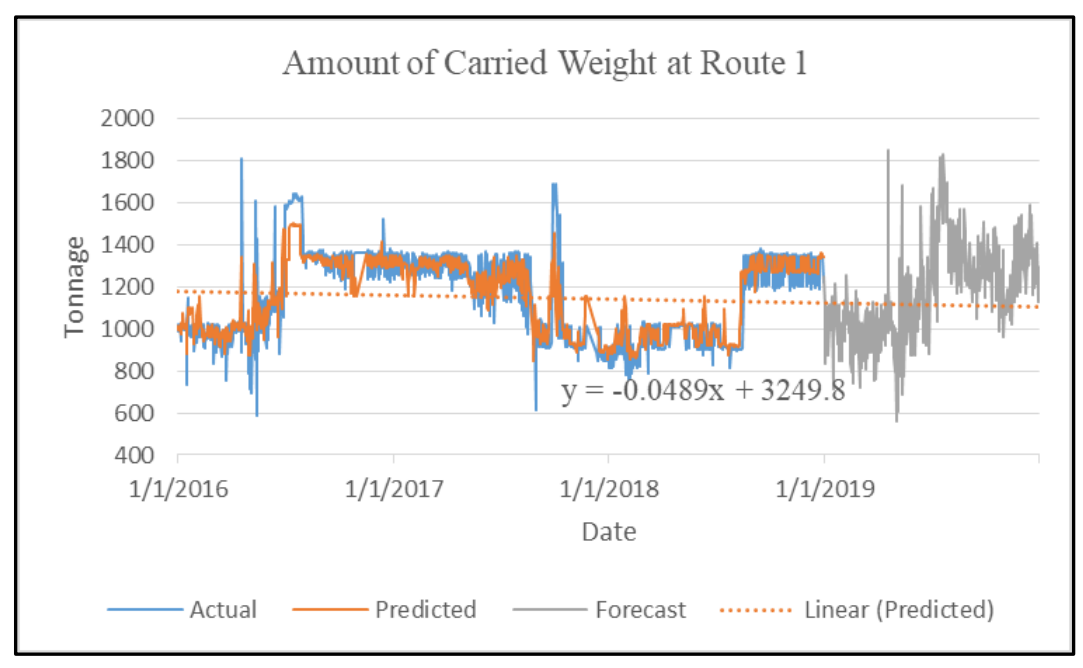

Figure 2. Amount of carried weight forecast for route 1

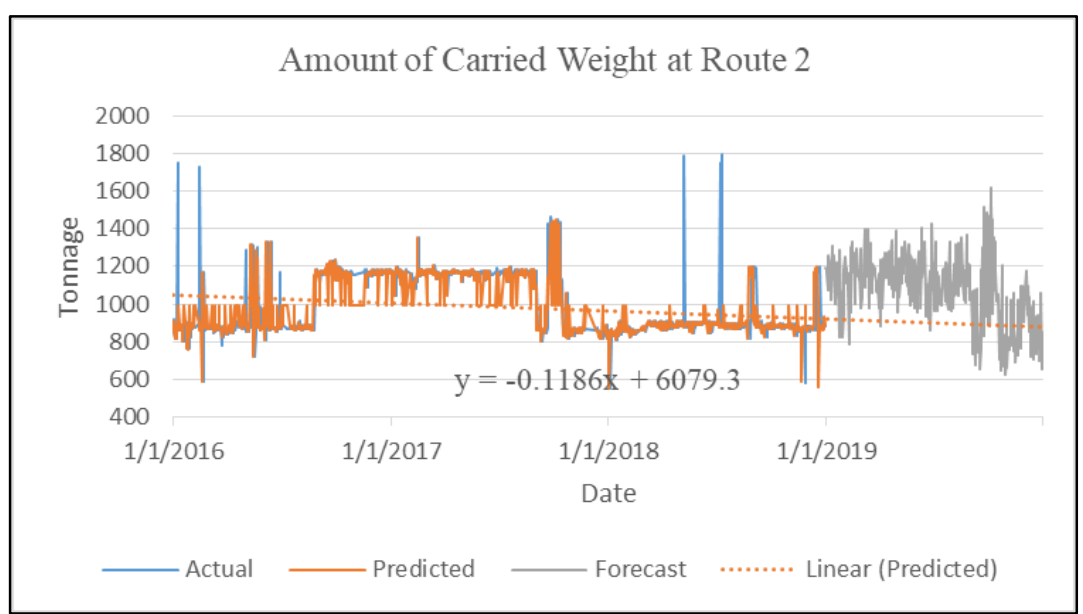

Figure 3. Amount of carried weight forecast for route 2

\section{CONCLUSION}

This paper presents the application of Artificial Neural Network (ANN) to predict the amount of carried of cargo train, using three training algorithms: Levenberg - Marquardt algorithm (LM) as a well performed algorithm to predict different set of carried weight data, Conjugate Gradient Descent (GCD) as a well perform algorithm for prediction of other sets of data and Quick Propagation (QP) as a new algorithm used to predict carried weight. The achieved results show the appropriateness of the Artificial Neural Network in predicting the amount of carried weight based on the correlation, fitness and test error values. Based on the RMSE and MAPE, LM shows the smallest values for Route 1 and Route 2 that carry cement cargos for KTMB customers.

Furthermore, the ANN model based on the best training algorithm found in the first phase of the study is used to forecast value of carried weight of cargo train for both routes in rail transportation system. Results show that the values of carried weight fluctuate and decline overtime for year 2019 (365 days ahead). It is hope that the results can help KTMB to plan the right amount to be carried by its cargo per trip in its effort to prevent form more derailments occurrence. At the same time, as the amount of carried weight is predicted to decline over time, KTMB can plan a strategic initiative in getting more customers while monitoring the right amount to carry each trip. 


\section{ACKNOWLEDGEMENTS}

The authors would like to thank the Ministry of Education Malaysia (MOE) and Malaysia Institute of Transport (MITRANS), UniversitiTeknologi MARA, Malaysia for supporting this project. Special thanks to KTMB Cargo team led by En Mohd Din for providing information and support throughout this study.

\section{REFERENCES}

[1] Goodall, C. How to reduce your carbon footprint. The Guardian, Retrieved https://www.theguardian.com/environment/2017/jan/19/howtoreduce -carbon-footprint.

[2] Noor, H. M. Semua 'tergelincir' apabila kereta api keluar landasan. Utusan Online, Retrieved https://www.utusan.com.my/rencana/utama/semua-tergelincir-apabila-kereta-api-keluar-landasan-1.519872, 2017.

[3] Kumarappa, K. M. Kereta api Kuang-Rawang terjejas. Mymetro, Retrieved https://www.hmetro.com.my/mutakhir/2017/09/266282/keretapikuang-rawang-terjejas.

[4] Bernama. (2017, November 23). The derailment disrupts KTM rail service. Malaymail, Retrieved https://www.malaymail.com/news/malaysia/2017/11/23/trainderailmen -disrupts-ktm-rail-services/1516919.

[5] Hussin, M. H. (2019, July 18). Tren dijangka beroperasi semula Isnin. Mymetro, Retrieved https://www.hmetro.com.my/mutakhir/2019/07/476835/tren-dijangka-beroperasi-semula-isnin.

[6] S. Verma et al. "ANN based method for improving gold price forecasting accuracy through modified Gradient Descent Methods”, IAES International Journal of Artificial Intelligence, vol. 9 (1), 2020.

[7] Hesam Karim et al., Comparison of Neural Network Training Algorithms for Classification of Heart Diseases, IAES International Journal of Artificial Intelligence, vol. /issue 7(4), pp. 185-189, 2018.

[8] Linawati, L., Sudarma, M \& Wisnawa, I. P.O. Forecasting rupiah exchange rate with learning vector quantization neural network, Indonesian Journal of Electrical Engineering and Computer Science, Vol 18 (1), 24-31, 2020.

[9] Berhil, S., Benlahmar, H. \& Labani, N. A review paper on artificial intelligence at the service of human resources management, Indonesian Journal of Electrical Engineering and Computer Science, Vol 18 (1), pp 32-40, 2020.

[10] Ab. Wahab, N., Mat Yasin, Z., Salim, N. A. \& Aziz, N. F. A. Artificial neural network-based technique for energy management prediction, Indonesian Journal of Electrical Engineering and Computer Science, Vol 17 (1), pp 94101, 2019.

[11] Amani, J., \& Moeini, R. Prediction of shear strength of reinforced concrete beams using adaptive neuro-fuzzy inference system and artificial neural network. Scientia Iranica, 19(2), 242-248, 2012.

[12] Barhmi, S. \& El Fatni, O. Hourly wind speed forecasting based on Support Vector Machine and Artificial Neural Networks, IAES International Journal of Artificial Intelligence, Vol 8, No 3, pp 286-291, 2019.

[13] Efendigil, T., \& Onut, S. An integration methodology based on fuzzy inference systems and neural approaches for multi-stage supply-chains. Computers \& Industrial Engineering, 62(2), 554-569, 2012.

[14] Rahman, M. N. A., Jafarzadeh-Ghoushchi, S., Wahab, D. A., \& Jafarzadeh-Ghoushji, M. Artificial Neural Network Modeling Studies to Predict the Amount of Carried Weight By Iran Khodro Transportation System. Life Science Journal, 11(SPEC. ISS. 2), 146-154, 2014.

[15] Ghoushchi, S. J., \& Rahman, M. N. A. Performance study of artificial neural network modelling to predict carried weight in the transportation system. International Journal of Logistics Systems and Management, 24(2), 200, 2016.

[16] Pokrajac, D., \& Lazarevic, A. Applications of unsupervised neural networks in data mining. In 7th Seminar on Neural Network Application and Elecctrical Engineering NEUREL, 17-20, 2004.

[17] Sayed A, Sardeshmukh M, \& Limkar, S. Optimisation Using Levenberg-Marquardt Algorithm of Neural Networks for Iris. In: Satapathy S, Udgata S, Biswal B (eds) Proceedings of the International Conference on Frontiers of Intelligent Computing: Theory and Applications (FICTA) 2013. Advances in Intelligent Systems and Computing, vol. 247. Springer, Cham.

[18] Xiao, Y., \& Zhu, H. A conjugate gradient method to solve convex constrained monotone equations with applications in compressive sensing. Journal of Mathematical Analysis and Applications, 405(1), 310-319, 2013.

[19] Chouhan, S.S., Kaul, A. \& Singh, U.P. Image segmentation using fuzzy competitive learning based counter propagation network. Multimed Tools Appl 78, 35263-35287, 2019.

[20] Fildes, R., Hibon, M., Makridakis, S., \& Meade, N. Generalising about univariate forecasting methods: further empirical evidence. International Journal of Forecasting, 14(3), 339-358, 1998.

[21] Yap, SZZ., Zahari, SM., Derasit, Z. \& Shariff, SSR. An iterative Newton-Raphson (NR) method on Lee-Carter parameter's estimation for predicting hospital admission rates, AIP Conference Proceedings, 1974 (1), Pages 020049, 2018.

[22] Yap, SZZ., Zahari, SM., Derasit, Z. \& Shariff, SSR. Comparing Methods for Lee-Carter Parameter's Estimation for Predicting Hospital Admission Rates, Proceedings of the Second International Conference on the Future of ASEAN (ICoFA), Volume 2, 361-372, 2018.

[23] Shariff, SSR., Maad, HA., Halim, NNA. \& Derasit, Z. Determining hotspots of road accidents using spatial analysis, Indonesian Journal of Electrical Engineering and Computer Science, Volume 9 (1), Pages 146-151, 2018.

[24] Ismaeel, S., Al-khazraji, A., \& Al-delimi, K. Fuzzy Information Modeling in a Database System. IAES International Journal of Artificial Intelligence (IJ-AI), Vol. 6, No. 1, pp. 1-7, 2017.

[25] Bennett, D. A. How can I deal with missing data in my study? Australian and New Zealand Journal of Public Health, 25(5), 464-469, 2001. 


\section{BIOGRAPHIES OF AUTHORS}
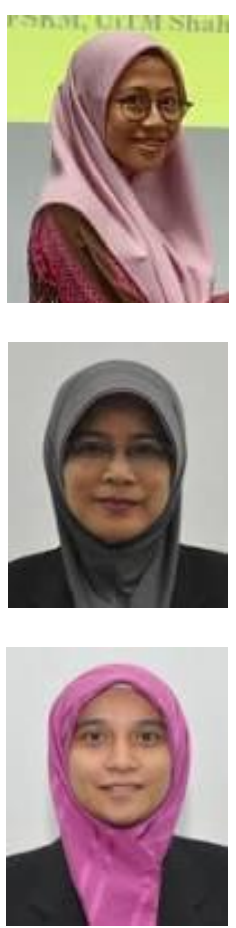

Siti Nasuha Zubir, she is a post graduate student in Master of Quantitative Sciences in Faculty of Computer and Mathematical Sciences, Universiti Teknologi MARA, Shah Alam.

Ts Dr S.Sarifah Radiah Shariff, she is a Senior Lecturer in Centre of Statistics and Decision Science Studies in Faculty of Computer and Mathematical Sciences, Universiti Teknlogi MARA, Shah Alam. Her expertise is in Supply Chain and Logistics Modelling. Currently she is attached to Malaysia Institut e of Transport, UiTM.

Dr Siti Meriam Zahari, she is a Senior Lecturer in Centre of Statistics and Decision Science Studies in Faculty of Computer and Mathematical Sciences, Universiti Teknlogi MARA, Shah Alam. Her expertise is in Econometrics and Time Series. 